\title{
SURFACE DEGRADATION OF COMPOSITE RESINS BY ACIDIC MEDICINES AND pH-CYCLING
}

\author{
Ana Carolina VALINOTI ${ }^{1}$, Beatriz Gonçalves NEVES ${ }^{2}$, Eduardo Moreira da SILVA ${ }^{3}$, Lucianne Cople MAIA ${ }^{4}$
}

1- DDS, Graduate student, Department of Pediatric Dentistry and Orthodontics, Dental School, Federal University of Rio de Janeiro, Rio de Janeiro, RJ, Brazil.

2- DDS, MSc, Graduate student, Private Practice, Department of Pediatric Dentistry and Orthodontics, Dental School, Federal University of Rio de Janeiro, Rio de Janeiro, RJ, Brazil.

3- DDS, MSc, PhD, Associate Professor Department of Restorative Dentistry, Dental School, Federal Fluminense University, Niterói, RJ, Brazil.

4- DDS, MSc, PhD, Associate Professor Department of Pediatric Dentistry and Orthodontics, Dental School, Federal University of Rio de Janeiro, Rio de Janeiro, RJ, Brazil.

Corresponding address: Dr. Eduardo Moreira da Silva - Universidade Federal Fluminense / Faculdade de Odontologia - Rua São Paulo, $\mathrm{n}^{\circ} 28$ - Campus Valonguinho, Centro, Niterói, RJ, Brasil - 24040-110 - Phone: +55-21-2629-9832. Fax: +55-21-2622-5739 - e-mail: emsilva@vm.uff.br

Received: February 8, 2008 - Modification: March 6, 2008 - Accepted: March 12, 2008

\begin{abstract}
$T$ degradation of four composite resins (microhybrid: TPH, Concept, Opallis and Nanofilled: Supreme). Thirty disc-shaped specimens $(\varnothing=5.0 \mathrm{~mm} /$ thickness $=2.0 \mathrm{~mm})$ of each composite were randomly assigned to 3 groups $(\mathrm{n}=10)$ : a control and two experimental groups, according to the acidic medicines evaluated. The specimens were finished and polished with aluminum oxide discs, and the surface roughness was measured by using a profilometer. After the specimens were submitted to a pHcycling regimen and immersion in acidic medicines for 12 days, the surface roughness was measured again. Two specimens for each material and group were analyzed by scanning electron microscopy (SEM) before and after pH-cycling. Data were analyzed by the Student's- $t$ test, ANOVA, Duncan's multiple range test and paired t-test $(\alpha=0.05)$. Significant increase in roughness was found only for TPH in the control group and TPH and Supreme immersed in Claritin ${ }^{\circledR}(\mathrm{p}<0.05)$. SEM analyses showed that the 4 composite resins underwent erosion and surface degradation after being subjected to the experimental conditions. In conclusion, although the roughness was slightly affected, the $\mathrm{pH}$-cycling and acidic medicines caused surface degradation of the composite resins evaluated. Titratable acidity seemed to play a more crucial role on surface degradation of composite resins than $\mathrm{pH}$.
\end{abstract}

Key Words: Composite resins. Surface degradation. pH-cycling. Acidic medicines. Microscopy, Electron, Scanning.

\section{INTRODUCTION}

Composite resins are widely used in restorative and pediatric dentistry. Most of the available composites contain a polymer matrix of dimethacrylate monomers, such as BisGMA, UDMA, and TEGDMA, inorganic filler particles coated with a methyl methacrylate-functional silane coupling agent to bond the filler to the organic matrix, and a photoinitiator system to allow photoactivation by light units ${ }^{14,19,23}$. These restorative materials are indicated for solving several problems, such as repairing teeth damaged due to caries, restoring enamel lost by traumas and abrasion, and also for esthetic reasons ${ }^{1}$.

Although the physical and mechanical properties of composite resins are indicators that predict the behavior of composite restorations, other aspects, such as material biodegradation, must be taken into account in the clinical performance of this type of restorative procedure. The critical oral environment conditions, i.e., $\mathrm{pH}$ changes and humidity, may increase resin composite biodegradation over time ${ }^{27}$. This phenomenon is a complex process that may lead the composite polymer matrix to collapse, causing several problems such as filler-polymer matrix debonding ${ }^{26}$, release of residual monomers ${ }^{22}$, and wear and erosion caused by food, chewing and bacterial activity ${ }^{18}$. This process may deteriorate the mechanical properties of the material ${ }^{27}$, and reduce the clinical life of composite resin restorations. Furthermore, surface disintegration of composite resins may increase wear and plaque retention, thus decreasing the longevity of the restoration ${ }^{10}$, and potentially increasing the risk of secondary caries.

Previously published studies have reported that acidic conditions show a tendency to degrade glass ionomer cements, polyacid modified composite resins, and composite resins $s^{1,10,17,28}$. Some medicines, considered acidic due to their low $\mathrm{pH}$ and high titratable acidity, may act as extrinsic agents 
of dental erosion, especially if consumed frequently ${ }^{8}$. These formulations are used on a regular basis and over long periods, especially by adults and children that present chronic diseases, and may be an example of potentially erosive agents of restorative materials. Up to now, however, there are no studies on the effect of acidic medicines on these materials.

The purpose of this study was to evaluate the effects of acidic medicines, under $\mathrm{pH}$-cycling conditions, on the surface roughness and degradation of 4 composite resins. The tested null hypothesis was that $\mathrm{pH}$-cycling and exposure to acidic medicines would not influence the roughness and surface degradation of the evaluated composite resins.

\section{MATERIAL AND METHODS}

Four composite resins were analyzed in this study: 3 microhybrid (TPH, Concept Advanced Magic Kids, and Opallis) and 1 nanofilled composite (Supreme). The material compositions and specifications are described in Table 1.

The characteristics of the acidic medicines used in this study are shown in Table 2 . The type and volume $(\mathrm{mL})$ of acid present in each medicine was obtained by direct contact with manufacturers. In addition, the medicines were analyzed with respect to $\mathrm{pH}$, titratable acidity and viscosity. The $\mathrm{pH}$ was measured with a pH meter (PM600, Analion, Ribeirão Preto, SP, Brazil). The titratable acidity was determined in duplicate by using the same $\mathrm{pH}$ meter. To detect the end point, $50 \mathrm{~g}$ of medicine solution was dissolved in $200 \mathrm{~mL}$ of water and titrated with $0.1 \mathrm{~N}$, using phenolphthalein. Claritin presented $\mathrm{pH} 9.68$ in the end point while Dimetapp presented $\mathrm{pH}$ 9.06. After that, $100 \mathrm{~g}$ of each medicine was dissolved in $150 \mathrm{~mL}$ of water to prepare new samples. The titratable acidity of each medicine was measured following gradual addition of $0.05 \mathrm{~N}$ sodium hydroxide $(\mathrm{NaOH})$ solution to the beaker until the end point. The correction factor of 0.89 was obtained by factorizing 0.01 $\mathrm{N} \mathrm{NaOH}$ solution with potassium biphthalate (C8H5KO4). The total volume of $\mathrm{NaOH}$ solution required to reach the end point multiplied by the correction factor of 0.89 corresponded to the titratable acidity value ${ }^{3}$. Viscosity measurements were carried out on a viscosimeter (HAAKE RheoStress 600 viscosimeter, Thermo Electron $\mathrm{GmbH}$, Karlsruhe, Germany) with a shear rate of $0.1-100 \mathrm{~s}^{-1}$ at $35^{\circ} \mathrm{C}$. The viscosity values were obtained at $20 \mathrm{~s}^{-1}$ shear rate, at which the medicines presented a constant viscosity value.

\section{Specimen Preparation}

Single increments of each composite resin were applied to an aluminum mould (diameter $=5 \mathrm{~mm}$ and thickness $=2.2$ $\mathrm{mm})$, covered with a polyester strip and a $0.1-\mathrm{mm}$-thick glass slide and light polymerized from the top for $20 \mathrm{~s}$, with an irradiance of $800 \mathrm{~mW} / \mathrm{cm}^{2}$ (Optilux 501, Kerr, Danbury, CT, USA). Thirty specimens were prepared for each resin composite. After setting, the specimens were finished and polished using medium, fine and superfine aluminum oxide abrasive disks (Soflex; 3M/ESPE, St. Paul, MN, USA). A single operator, using a low-speed handpiece without water cooling, performed this procedure.

\section{Baseline Roughness Measurement}

The surface roughness of each specimen $(R a-\mu \mathrm{m})$ was measured using a profilometer (Surftest SJ 201, Mitutoyo Co, Kawasaki, Japan). Three roughness measurements spaced at $60^{\circ}$ were recorded for each specimen (cut-off length of 0.25 $\mathrm{mm}$ ). The mean value of three measurements was recorded as the surface roughness for each specimen.

TABLE 1- Composition and specifications of composite resins used in this study

Composite resins Composition Manufacturer

TPH 3

Concept Advanced Magic $\mathrm{Kids}^{\odot}$

Opallis

Supreme
Polymer matrix: Bis-GMA, Bis-EMA and TEGDMA

Filler: 57 vol\% of Ba-Al-borosilicate glass and colloidal silica with mean particle size of $0.8 \mu \mathrm{m}$

Polymer matrix: Bis-GMA,UDMA and Esther of methacrylic acid

Filler: 67 vol\% of Ba-Al-silicate glass with mean particle size of $0.4 \mu \mathrm{m}$.

Polymer matrix: BisGMA, BisEMA, and TEGDMA Filler: 67 vol\% Ba-Al silicate glass and silicon dioxide with mean particle size of $0.5 \mu \mathrm{m}$.

Polymer matrix: Bis-GMA, Bis-EMA, UDMA TEGDMA

Filler: 59.5 vol\% combination of aggregated zirconia/silica cluster filler with primary particles size of $5-20 \mathrm{~nm}$, and non-agglomerated $20 \mathrm{~nm}$ silica filler.
Denstply Ind. e Com. Ltda., Petrópolis, RJ, Brazil

Vigodent, Rio de Janeiro, RJ, Brazil

FGM, Joinville, SC, Brazil

3M/ESPE, St. Paul, MN, USA 
TABLE 2- Characteristics of the acidic medicines used in the present study

\begin{tabular}{|c|c|c|}
\hline \multirow[t]{2}{*}{ Characteristics } & \multicolumn{2}{|l|}{ Medicines } \\
\hline & $\begin{array}{l}\text { Claritin }^{\circledR} \text { (E1) } \\
\text { (Schering-Plough, São Paulo, SP, Brazil) }\end{array}$ & $\begin{array}{l}\text { Dimetapp Elixir }{ }^{\circledR}(E 2) \\
\text { (Wyeth-Whitehall, São Paulo, SP, } \\
\text { Brazil) }\end{array}$ \\
\hline Batch Number & 701 & $46139 A$ \\
\hline Active Principle & Loratadine & $\begin{array}{l}\text { Brompheniramine } \\
\text { and Pseudoephedrine }\end{array}$ \\
\hline $\mathrm{pH}$ & 2.57 & 2.51 \\
\hline $\begin{array}{l}\text { Titratable acidity mean } \\
\text { volume of } 0.05 \mathrm{~N} \mathrm{NaOH} \\
(\mathrm{mL})\end{array}$ & $41.83 \mathrm{~mL}$ & $36.31 \mathrm{~mL}$ \\
\hline Viscosity at $20 \mathrm{~s}^{-1}$ & 19.7 & 13.3 \\
\hline $\begin{array}{l}\text { Acid content according to } \\
\text { manufacturers ( } \mathrm{mg} / \mathrm{mL})\end{array}$ & $\begin{array}{l}\text { Citric Acid } \\
(8.8 \mathrm{mg} / \mathrm{mL})\end{array}$ & $\begin{array}{l}\text { Citric Acid } \\
(7.5 \mathrm{mg} / \mathrm{mL})\end{array}$ \\
\hline
\end{tabular}

\section{pH-Cycling and Experimental Protocol}

After the baseline roughness measurement, the 30 specimens of each composite resin were randomly assigned to 3 groups $(n=10)$ according to the immersion medium [E1 Claritin $^{\circledR}$; E2 - Dimettap ${ }^{\circledR}$ and C (control) - deionized water] and submitted to a $24-\mathrm{h} \mathrm{pH}$-cycling regimen, using the model proposed by White ${ }^{30}(1987)$, and to acidic medicines. The experimental protocol is shown in Figure 1. The compositions of the solutions were: demineralizing $(3 \mathrm{mmol} / \mathrm{L}$ calcium, 3 $\mathrm{mmol} / \mathrm{L}$ phosphate and $50 \mathrm{~mL} / \mathrm{L}$ acetic acid in a $\mathrm{pH}$ adjusted to 4.5 with $\mathrm{NaOH})^{9}$ and remineralizing $(1.54 \mathrm{mmol} / \mathrm{L}$ of calcium, $1.54 \mathrm{mmol} / \mathrm{L}$ of phosphate, $20 \mathrm{mmol} / \mathrm{L}$ of acetic acid and 0.308 $\mathrm{g}$ of ammonium acetate with $\mathrm{pH}$ adjusted to 6.8 with potassium chloride at $\left.37^{\circ} \mathrm{C}\right)^{15}$. The amount of each medicine, deionized water, remineralizing and demineralizing solution for each group was $10 \mathrm{~mL}$. The medicines and deionized water were replaced at every immersion time and the solutions were changed daily. After each immersion in medicines, the specimens were rinsed with $20 \mathrm{~mL}$ of deionized water. These storage regimens were repeated uninterruptedly for 12 days. After the 12th day, the surface roughness was measured again, exactly as described for baseline.

\section{Scanning Electronic Microscopy (SEM) Analysis}

SEM analysis was performed to show the surface aspects of composite resins before and after the experimental protocol. Two additional disc-shaped specimens of each material were produced and set aside before $\mathrm{pH}$-cycling, for later examination, and one pair of each group was randomly selected after $\mathrm{pH}$-cycling. These specimens were mounted on aluminum stubs, sputter-coated with gold, and examined with a scanning electronic microscope (JEOL-JSM; 6460LV, Tokyo, Japan), with an acceleration voltage of $15 \mathrm{kV}$. SEM micrographs at $x$ 5,000 magnification were taken.
Initial Roughness

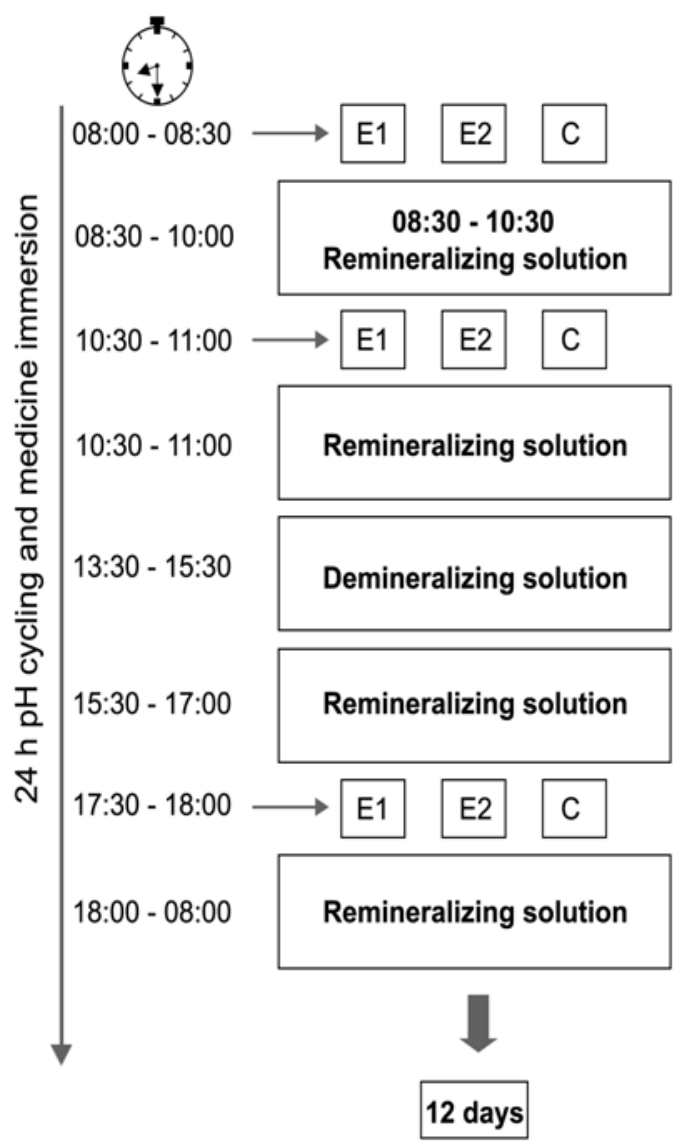

Final Roughness

FIGURE 1-Schematic design of the $\mathrm{pH}$-cycling and medicine immersion 


\section{Statistical Analysis}

Statistical analysis was performed using Statgraphics 5.1 Software (Manugistics, Rockville, MD, USA). One-way ANOVA and Duncan's multiple range test were used to analyze the roughness data of the composite resins before $\mathrm{pH}$-cycling. Paired t-test was applied to check for differences between surface roughness before and after $\mathrm{pH}$-cycling. All statistical analyses were performed at a level of significance of $\alpha=0.05$.

\section{RESULTS}

\section{Surface Roughness}

The results of surface roughness before $\mathrm{pH}$-cycling are shown in Figure 2. One-way ANOVA detected statistically significant differences among the composite resins $(p=0.0331)$. Duncan's test showed that the roughness of

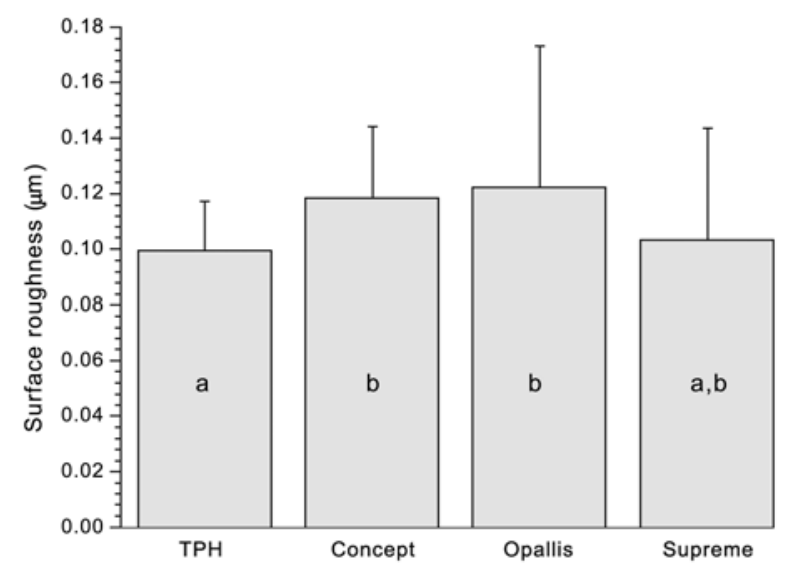

FIGURE 2- Surface roughness before $\mathrm{pH}$-cycling. Columns with the same letters do not differ significantly $(\alpha=0.05)$
TPH was statistically similar to that of Supreme and significantly lower than that of Concept and Opallis $(\mathrm{p}<0.05)$. Nevertheless, the roughness of Supreme, Opallis and Concept did not differ significantly from each other $(\mathrm{p}>0.05)$. The results of paired t-test are shown in Table 3. Only TPH and Supreme immersed in Claritin ${ }^{\circledR}$, and TPH immersed in deionized water (control) presented a significant increase in surface roughness $(\mathrm{p}<0.05)$.

\section{SEM Analysis}

All composite resins showed a smooth surface before $\mathrm{pH}$-cycling (Figure 3). After $\mathrm{pH}$-cycling, all materials presented some erosion (Figures 4-6). In the control group, this aspect was more evident for TPH (Figure 4a), which presented more accentuated matrix degradation. In general, specimens immersed in Claritin ${ }^{\circledR}$ (Figure 5) presented more structural defects than those immersed in Dimetapp ${ }^{\circledR}$ (Figure 6). Damage on composite surface was more evident especially for TPH (Figure 5a), in which several filler particles were observed protruding from the surface, as well as voids suggestive of particle loss. TPH also showed a great deal of degradation when immersed in Dimetapp ${ }^{\circledR}$ (Figure 6a). Irrespective of the acidic medicine, surface degradation presented by Opallis and Concept was similar, with spaced pits suggesting less matrix loss (Figures 5b, 5c, 6b and 6c). Supreme was the composite that most resisted to the action of Dimetapp ${ }^{\circledR}$ (Figure 6d).

TABLE 3- Results of paired t-test for surface roughness means (Ra; $\mathrm{mm}$ ) before and after $\mathrm{pH}$-cycling

\begin{tabular}{|c|c|c|c|c|}
\hline & Before pH-cycling & After pH-cycling & $\mathbf{P}$ & Roughness variation \\
\hline TPH E1 & $0.089(0.012)$ & $0.101(0.012)$ & $0.030^{*}$ & 0.0129 \\
\hline TPH E2 & $0.112(0.020)$ & $0.114(0.020)$ & 0.804 & 0.0023 \\
\hline TPH Control & $0.096(0.001)$ & $0.117(0.015)$ & $0.003^{*}$ & 0.0213 \\
\hline Concept E1 & $0.116(0.032)$ & $0.124(0.026)$ & 0.554 & 0.008 \\
\hline Concept E2 & $0.119(0.019)$ & $0.130(0.009)$ & 0.109 & 0.0114 \\
\hline Concept Control & $0.121(0.025)$ & $0.115(0.018)$ & 0.589 & -0.0054 \\
\hline Opallis E1 & $0.145(0.083)$ & $0.128(0.023)$ & 0.537 & -0.0173 \\
\hline Opallis E2 & $0.110(0.015)$ & $0.110(0.015)$ & 0.932 & -0.0006 \\
\hline Opallis Control & $0.11190 .016)$ & $0.106(0.019)$ & 0.518 & -0.0054 \\
\hline Supreme E1 & $0.091(0.021)$ & $0.117(0.024)$ & $0.025^{*}$ & 0.0253 \\
\hline Supreme E2 & $0.118(0.061)$ & $0.105(0.024)$ & 0.554 & -0.0126 \\
\hline Supreme Control & $0.101(0.024)$ & $0.101(0.027)$ & 0.985 & -0.0002 \\
\hline
\end{tabular}

* Significant at $\alpha=0.05$ 

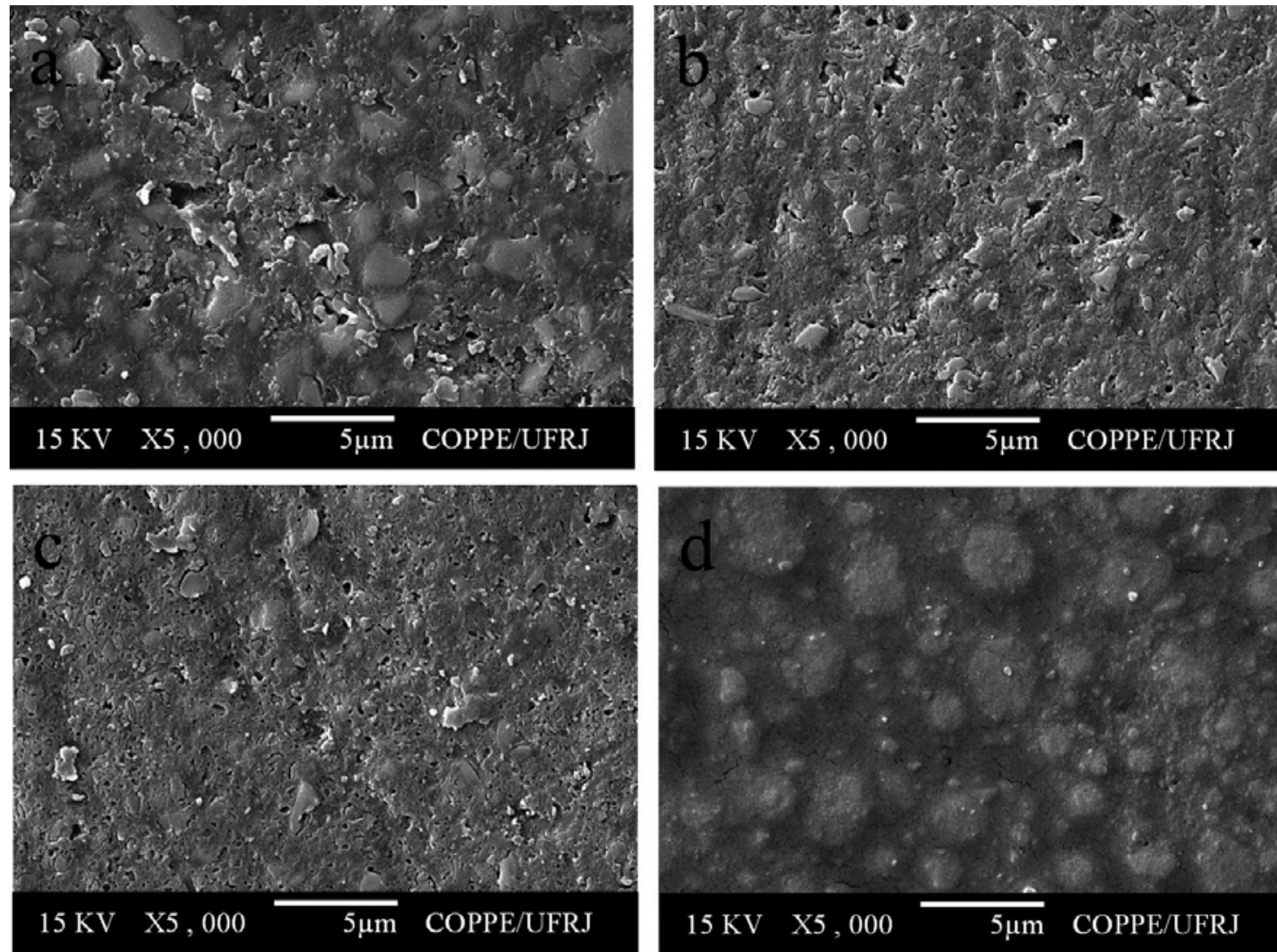

FIGURE 3- Representative SEM micrographs of resin-based composites before pH-cycling. (a) TPH, (b) Concept, (c) Opallis and (d) Supreme
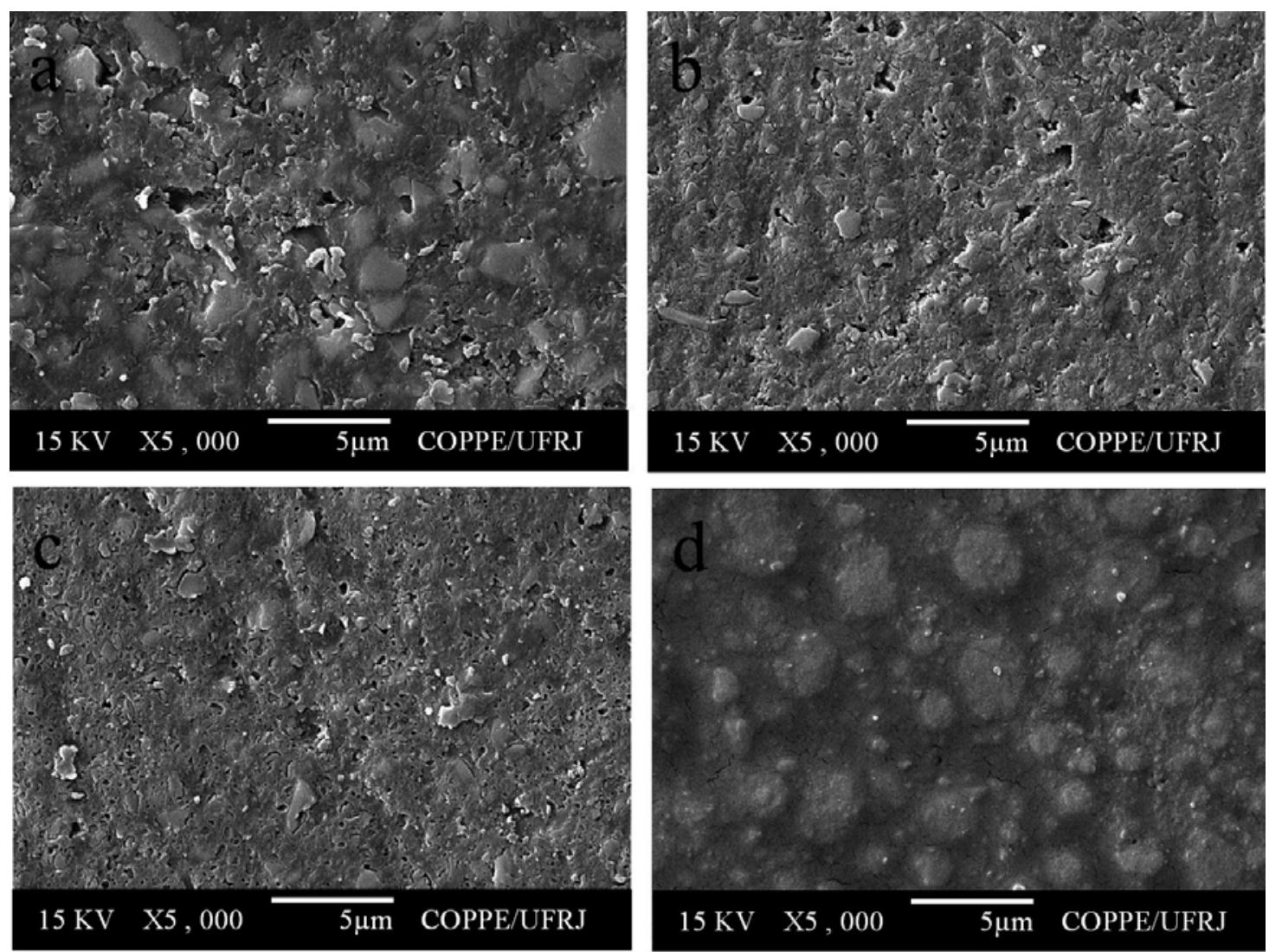

FIGURE 4- Representative SEM photomicrographs of resin-based composites after pH-cycling and immersion in distilled water, control group. (a) TPH, (b) Concept, (c) Opallis and (d) Supreme 

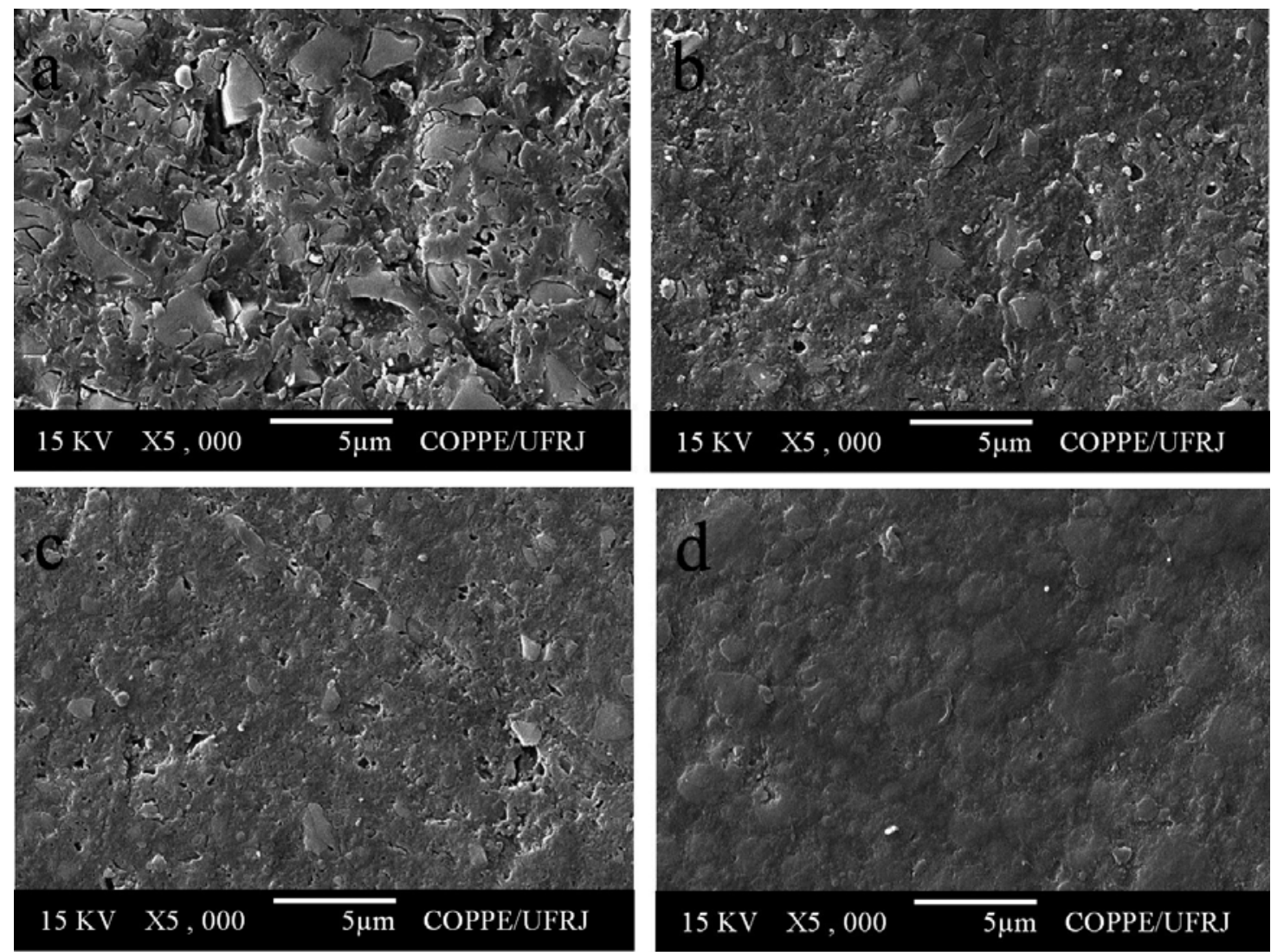

FIGURE 5- Representative SEM photomicrographs of resin-based composites after $\mathrm{pH}$-cycling and immersion in Claritin ${ }^{\circledR}$. (a) TPH, (b) Concept, (c) Opallis and (d) Supreme
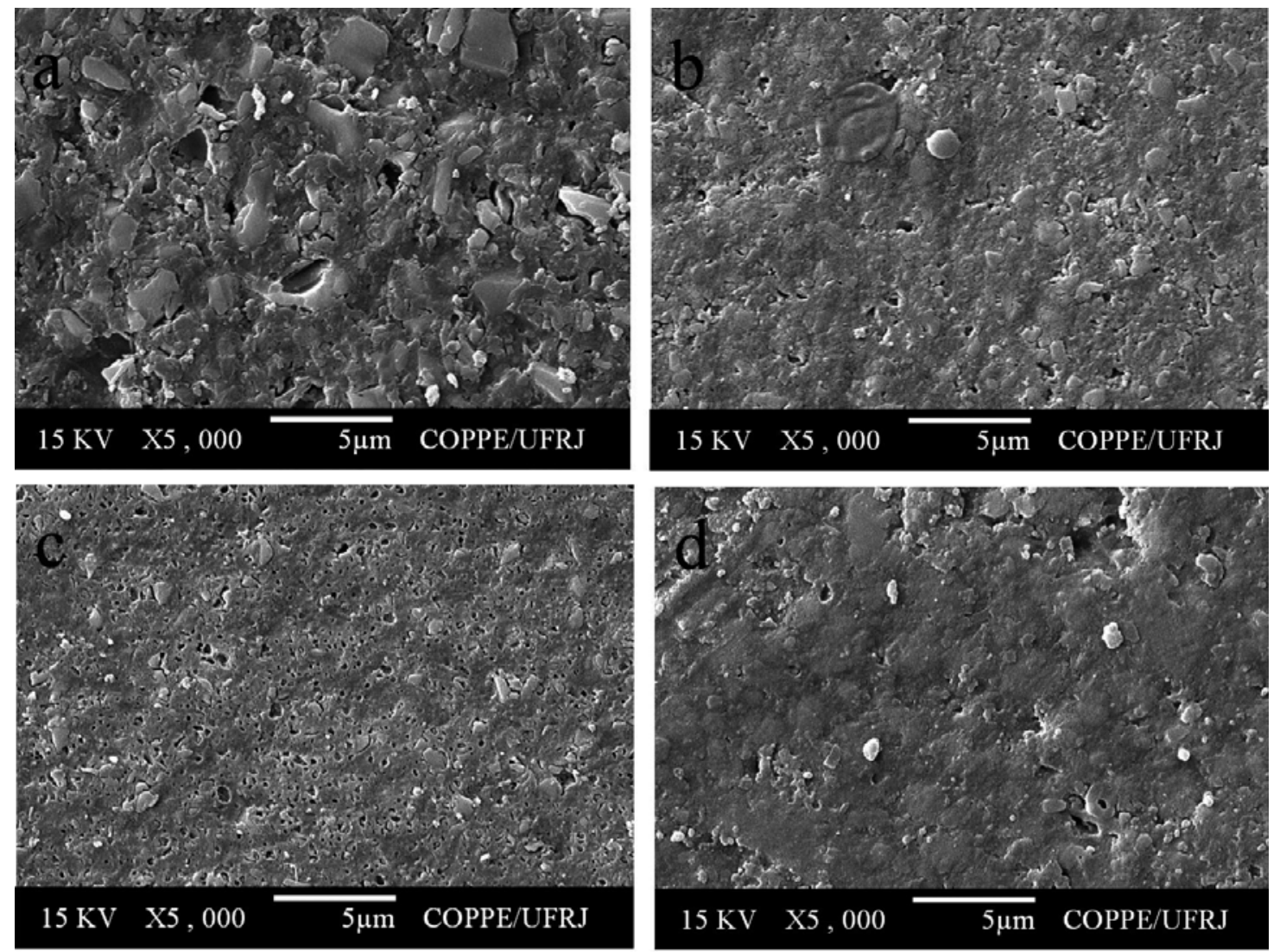

FIGURE 6- Representative SEM photomicrographs of resin-based composites after $\mathrm{pH}$-cycling and immersion in Dimetapp ${ }^{\circledR}$. (a) TPH, (b) Concept, (c) Opallis and (d) Supreme 


\section{DISCUSSION}

While only TPH and Supreme immersed in Claritin ${ }^{\circledR}$ and TPH immersed in deionized water (control group) presented an increase in surface roughness, all composite resins showed surface degradation after immersion in acidic medicines. Thus, the null hypothesis of the present study was rejected. The widespread use of resin-based restorative materials and their exposure to the harsh conditions of the oral environment require them to be resistant to degradation ${ }^{4}$. However, under acidic conditions, restorative materials, including the composite resins analyzed in this study, may suffer degradation over time, which can be predicted by changes in surface topography and roughness, decrease in hardness and wear resistance and substance loss ${ }^{11,12,17,24,25}$. All these shortcomings will decrease the material's physicalmechanical properties as well as create a predisposing factor to bacterial colonization, which could potentially increase the risk of oral diseases ${ }^{25}$.

The medicines selected for this study present characteristics that may increase the erosive potential to teeth, i.e., low endogenous $\mathrm{pH}$, high titratable acidity and presence of citric acid $^{8,29}$. Claritin ${ }^{\circledR}$ is an antihistamine frequently indicated for chronic diseases, for example, allergies, and Dimetapp ${ }^{\circledR}$ elixir is indicated to relieve symptoms of colds, upper respiratory infections and allergies. Published studies have shown that acidic media produce surface alterations in resin restorative materials ${ }^{28,31}$. In one of these studies, however, the materials were immersed in acid media for long and uninterrupted periods of time ${ }^{28}$. This model probably overestimates the time in which the human plaque remains acid. In the present study, the $\mathrm{pH}$ cycling model was used in an attempt to simulate the oral conditions as closely as possible, thus allowing more realistic results about the behavior of the resin materials analyzed.

In the present study, the analysis of roughness data before $\mathrm{pH}$-cycling showed hat TPH presented similar behavior to that of Supreme and lower roughness than Concept and Opallis (Figure 2). After pH-cycling and immersion in distilled water and Claritin ${ }^{\circledR}$, however, TPH presented a significant increase in roughness (Table 3 ). This finding could be due to the filler particle characteristics of this material. Previous studies have shown that resin materials that have larger filler particles presented greater surface micromorphology changes when submitted to acidulated phosphate fluoride (APF) gel, i.e., a fluoride compound that has a low $\mathrm{pH}^{5,29}$. Among the resin materials analyzed in this study, TPH presents the largest filler particles, $0.8 \mu \mathrm{m}$, (Table 1), which has probably contributed to the increase of its roughness after $\mathrm{pH}$-cycling. Moreover, Supreme composite also showed an increase in roughness after $\mathrm{pH}$-cycling and immersion in Claritin ${ }^{\circledR}$. The same rationale as for TPH behavior may be used to explain this result. Although the primary particle size of Supreme is 20 $\mathrm{nm}$, it is reasonable to speculate that the $\mathrm{Zr}$-Si cluster of 0.6$1.4 \mu \mathrm{m}$ may have contributed to the observed increase in roughness. Furthermore, the fact that Opallis and Concept have a mean filler particle size close to the same value (Table
1) and did not present significant changes in roughness after $\mathrm{pH}$-cycling and immersion in the evaluated medicines, reinforces the role that filler size plays on surface degradation of resin-based restorative materials.

The SEM analysis showed that irrespective of immersion in acidic medicines, all composite resins presented surface changes after $\mathrm{pH}$-cycling, which could be considered as a process of degradation and erosion of the polymer matrix. Several protruding particles, voids and cracks were observed in all specimens analyzed (Figures 4-6). These findings are in agreement with those of a previous study ${ }^{28}$, which analyzed the changes in surface micromorphology of several resin-based materials submitted to a $\mathrm{pH}$-cycling regimen. This study ${ }^{28}$ showed several filler particles protruding from the surface of a microfilled composite, which was attributed to polymer matrix degradation. Moreover, the polymer matrix of a hybrid composite and a polyacid modified composite resin showed several voids, which were associated with a possible degradation of the surrounding resin matrix or silane coupling agent and loss of filler particles.

When comparing the roughness and SEM results, some interesting aspects can be discussed. Figure 2 shows that, at baseline, TPH presented roughness similar to that of Supreme and lower than that of Opallis and Concept. After pH-cycling, however, only TPH and Supreme showed a significant increase in roughness (Table 3). Given that it has already been proved that composite materials with high roughness values tend to show increased roughness after acid challenges, this result was unexpected. ${ }^{30}$ Moreover, Figures 4 and 5 show that TPH and Supreme suffered more degradation than Opallis and Concept. The only reasonable explanation for these results could be the higher polymer matrix content in the compositions of TPH and Supreme (Table 1). Wongkhantee, et al. ${ }^{31}$ (2006) showed a greater reduction in hardness after immersion in acidic drinks, for a microfilled composite when compared to an universal hybrid composite, and claimed that this result was influenced by the higher organic matrix content presented by microfilled composite. Since TPH and Supreme present 10 and 7.5 vol\% less polymer matrix, respectively than Opallis and Concept (Table 1), the same rationale of the aforementioned study might be used to explain the behavior of TPH and Supreme, as regards roughness, after $\mathrm{pH}$-cycling and acidic medicines immersion.

Comparing Figures 5 and 6, it can be seen that irrespective of changes in roughness, Claritin ${ }^{\circledR}$ had a more aggressive effect than that of Dimetapp ${ }^{\circledR}$. Since both medicines have approximately the same $\mathrm{pH}$ (Table 2), it is may be assumed that this finding is related to the titratable acidity. ${ }^{6}$ The probable mechanism of acidity in composite resin degradation may be explained by the hydrolysis of ester radicals present in dimethacrylate monomers, i.e. BisGMA, Bis-EMA, UDMA and TEGDMA ${ }^{7,20}$. Although previous studies assumed $\mathrm{pH}$ as a reliable indicator of the acidity of drinks ${ }^{21,31}$, this parameter gives only the initial concentration of ${ }^{+} \mathrm{H}$ ions, and does not represent the presence of undissociated acid in the medium. On the other hand, titratable acidity can be considered as a more accurate 
measure of the total acid content present in substances, and may represent their erosive effect more realistically ${ }^{6,16}$. The values of citric acid presented in Table 2 (manufacturers' information) agree with this assumption. Citric acid is an organic acid that may produce high levels of tooth erosion, possibly due to its strong chelating properties ${ }^{13}$, and some previous studies have shown that this acid may produce harmful effects on resin restorative materials ${ }^{7,20}$.

From a clinical point of view, the higher viscosity presented by Claritin ${ }^{\circledR}$ (Table 2) may be considered as a crucial factor in composite resin degradation. It is reasonable to suppose that a more viscous medicine will stay in contact with the surface of composite restorations for a longer period, thus increasing its harmful effect ${ }^{6}$. However, since the specimens in the present study were rinsed with distilled water after immersion in the acidic medicines, their viscosity certainly did not interfere on the composite resin degradation.

\section{CONCLUSIONS}

From the experimental conditions adopted in this study, it may be concluded that although the roughness was only slightly affected, $\mathrm{pH}$-cycling and immersion in acidic medicines caused surface degradation of the tested composite resins. Titratable acidity seemed to play a more crucial role on surface degradation of composite resins than $\mathrm{pH}$. Moreover, composite resins with large filler particles might be more susceptible to degradation when submitted to acidic challenges.

\section{ACKNOWLEDGEMENTS}

The authors would like to thank CNPq (Brazilian National Council for Scientific and Technological Development) for the research grant (308029/2006-2), FAPERJ (Rio de Janeiro State Carlos Chagas Foundation for Research Funding) (E26/171.241/2006) and the Brazilian Government agency CAPES for the financial support for this project.

\section{REFERENCES}

1- Aliping-Mckenzie M, Linden RWA, Nicholson JW. The effect of Coca-Cola and fruit juices on the surface hardness of glass-ionomers and compomers. J Oral Rehabil. 2004;31:1046-52.

2- Asmussen E. Softening of BISGMA-based polymers by ethanol and by organic acids of plaque. Scand J Dent Res. 1984;92:257-61.

3- Association of Official Analytical Chemist. Official methods of analysis. Sugars and Sugar Products; 1966. p. 40.

4- Bagheri R, Tyas MJ, Burrow MF. Subsurface degradation of resinbased composites. Dent Mater. 2007;23:944-51.

5- Benderli Y, Gökçe K, Kazak M. Effect of APF gel on micromorphology of resin modified glass-ionomer cements and flowable compomers. J Oral Rehabil. 2005,32:669-75.
6- Cairns AM, Watson M, Creanor SL, Foye RH. The $\mathrm{pH}$ and titratable acidity of a range of diluting drinks and their potential effect on dental erosion. J Dent. 2002;30:313-7.

7- Chadwick RG, McCabe JF, Walls AWG, Storer R. The effect of storage media upon the surface microhardness and abrasion resistance of three composites. Dent Mater. 1990;6:123-8.

8- Costa CC, Almeida ICS, Costa LC Filho. Erosive effect of antihistamine-containing syrup on primary enamel and its reduction by fluoride dentifrice. Int J Paediatr Dent. 2006;16:174-80.

9- Damato FA, Strang R, Stephen KW. Effect of fluoride concentration on remineralization of carious enamel: an in vitro pH-cycling study. Caries Res. 1990;24:174-80.

10- De Witte AMJC, De Maeyer EAP, Verbeeck RMH. Surface roughening of glass ionomer cements by neutral NaF solutions. Biomaterials. 2003;24:1995-2000.

11- Gao F, Matsuya S, Ohta M, Zhang J. Erosion process of lightcured and conventional glass ionomer cements in citrate buffer solution. Dent Mater J. 1997;16:170-9.

12- Jaeggi T, Gruninger A, Lussi A. Dental erosion. Monogr Oral Sci. 2006;20:200-14

13 - Jarvinen VK, Rytomaa H, Heinonen OP. Risk factors in dental erosion. J Dent Res. 1991;70:942-7.

14- Kalachandra S, Taylor DF, Mc Grath JE, Sankarapandian M, Shobha HK. Structure- property relationships in dental composites based on polydimethacrylates. Polymer Prepr. 1997;38:94-5.

15-Lammers PC, Borggreven JMPM, Briessens FCM. Acidsusceptibility of lesions in bovine enamel after remineralization at different fluoride concentrations. J Dent Res. 1991;70:1486-90.

16- Larsen MJ, Nyvad B. Enamel erosion by some soft drinks and orange juices relative to their $\mathrm{pH}$, buffering effect and contents of calcium phosphate. Caries Res. 1999;33:81-7.

17- Nicholson JW, Millar BJ, Czarnecka H, Limanowska-Shaw H. Storage of polyacid-modified resin composites ("compomers") in lactic acid solution. Dent Mater. 1999;15:413-6.

18- Oilo G. Biodegradation of dental composites/glass ionomer cements. Adv Dent Res. 1992;6:50-4.

19- Peutzfeldt A. Resin composites in dentistry: the monomer systems. Eur J Oral Sci. 1997;105:97-116.

20- Prakki A, Cilli R, Mondelli RFL, Kalachandra S, Pereira JC. Influence of $\mathrm{pH}$ environment on polymer based dental material properties. J Dent. 2005;33:91-8.

21 - Rugg Gunn AJ, Maguire A, Gordon PH, McCabe JF, Stephenson G. Comparison of erosion of dental enamel by four drinks using an intraoral appliance. Caries Res. 1998;32:337-43.

22 - Ruyter IE. Physical and chemical aspects related to substances released from polymer materials in an aqueous environment. Adv Dent Res. 1995;9:344-7.

23 - Sideridou I, Tserki V, Papanastasiou G. Effect of chemical structure on degree of conversion in light-cured dimethacrylate-based dental resins. Biomaterials. 2002;23:1819-29.

24-Sidhu SK, Sherriff M, Watson TF. In vivo changes in roughness of resin-modified glass ionomer materials. Dent Mater. 1997;13:20813. 
25-Silva RC, Zuannon ACC. Surface roughness of glass ionomer cements indicated for atraumatic restorative treatment. Braz Dent J. 2006;17:106-9

26- Söderholm KJ, Mukherjee R, Longmate J. Filler leachability of composites stored in distilled water or artificial saliva. J Dent Res. $1996 ; 75: 1692-9$

27- Söderholm KJ, Zigan M, Ragan M, Fischlschweiger W, Bergman M. Hydrolytic degradation of dental composites. J Dent Res. 1984;63:1248-54

28 - Turssi CP, Hara AT, Serra MC, Rodrigues AL Jr. Effect of storage media upon the surface micromorphology of resin-based restorative materials. J Oral Rehabil. 2002;29:864-71.

29- Turssi CP, Magalhães CS, Serra MC. Effect of fluoride gels on micromorphology of resin-modified glass ionomer cements and polyacid-modified resin composites. Quintessence Int. 2001;32:5717.

30 - White DJ. Reactivity of fluoride dentifrices with artificial caries I. Effect on early lesions: F uptake, surface hardening and remineralization. Caries Res. 1987;21:126-40.

31- Wongkhantee S, Patanapiradej V, Maneenut C, Tantbirojn D. Effect of acidic food and drinks on surface hardness of enamel, dentine, and tooth-colored filling materials. J Dent. 2006;34:21420 . 